\title{
Acute myocardial infarction with normal coronary arteries in a case of polyarteritis nodosa: possible role of coronary
} artery spasm

\author{
R.M. Rajani, B.V. Dalvi, S.A. D’Silva, Y.Y. Lokhandwala and P.A. Kale \\ Department of Cardiology, King Edward VII Memorial Hospital, Parel, Bombay 400 012, India
}

\begin{abstract}
Summary: A 20 year old man with no previous history of heart disease presented with acute left ventricular failure following extensive anterior wall myocardial infarction. Selective angiography revealed multiple aneurysms in the renal, mesenteric and hepatic arteries with an infarct in the lower pole of the right kidney. These findings, along with the presence of circulating hepatitis B surface antigen favoured the diagnosis of polyarteritis nodosa. In view of normal coronary angiogram and absence of myocardial vasculitis, coronary vasospasm was implicated as the cause of myocardial infarction. Such an occurrence, which could have different therapeutic and diagnostic implications, has not, to our knowledge, been previously described in polyarteritis nodosa.
\end{abstract}

\section{Introduction}

Involvement of the cardiovascular system is reported in $33-66 \%$ of cases of polyarteritis nodosa (PAN). ${ }^{1}$ Although acute myocardial infarction is not uncommon, coronary arteries in such patients are always found to be completely or partially occluded. ${ }^{2}$ We report a case of PAN with acute myocardial infarction and normal coronary arteries.

\section{Case report}

A 20 year old male presented with excruciating substernal chest pain and breathlessness of 2 hours duration. On examination, there was evidence of poor peripheral circulation with a blood pressure of $110 / 80 \mathrm{mmHg}$. Cardiovascular assessment revealed mild cardiomegaly, a dyskinetic segment, left ventricular third heart sound and bilateral basal crackles.

His electrocardiogram showed extensive anterior wall myocardial infarction (Figure 1). There was marked elevation of serum creatine kinase MB fraction. He responded well to intravenous venodilators, diuretics and positive inotropic agents. Two days after the episode, he was detected to have persistent hypertension $(170 / 116 \mathrm{mmHg})$ which was controlled with oral hydrochlorthiazide and nifedipine. His laboratory investigations revealed haemoglobin of $10.8 \mathrm{~g} / \mathrm{dl}$, normocytic

Correspondence: B.V. Dalvi, D.M.

Accepted: 7 August 1990 normochromic red blood cells, white blood cell count of $11.4 \times 10^{9} / 1$ (7\% eosinophils). His eryth rocyte sedimentation rate was $80 \mathrm{~mm}$ at the end of 1 hour, and serum creatinine was $206 \mathrm{mmol} / \mathrm{l}$. He had hepatitis B surface antigen (HBsAg), antinuclear antibodies (1:80 dilution), cryoglobulins and a weakly positive RA factor (1:20 dilution). Circulating immune complexes were present with reduction of C3 levels of $24 \mathrm{mg} / \mathrm{dl}(60-110 \mathrm{mg} / \mathrm{dl})$. His VDRL was negative and antibodies to doublestranded DNA were not detected. His lipid profile did not reveal evidence of hypercholesterolaemia. A two dimensional echocardiogram, done one week later, showed apical and anterolateral akinesia with hypokinesia of the distal one third of the septum. Basal interventricular septum, diaphragmatic and posterobasal segments were contracting normally. Global left ventricular ejection fraction was $30 \%$. There were no clots, vegetations or tumour masses. Pericardium showed no abnormality. At cardiac catheterization, regional wall motion abnormalities seen on echocardiogram were confirmed. Coronary angiography showed normal coronary arteries (Figure $1 \mathrm{a}$ and $b$ ). He was subjected to right ventricular endomyocardial biopsy which revealed mild myocardial hypertrophy. There was no evidence of myocarditis. Kidney biopsy showed no evidence of small or medium vessel involvement. Abdominal aortogram along with renal, mesenteric and splanchnic angiography revealed multiple aneurysms in the renal, hepatic and mesenteric arteries with an infarct in the lower pole of the right kidney (Figure $2 \mathrm{a}$ and $\mathrm{b}$ ). The patient was discharged on hydrochlorthiazide and 
a

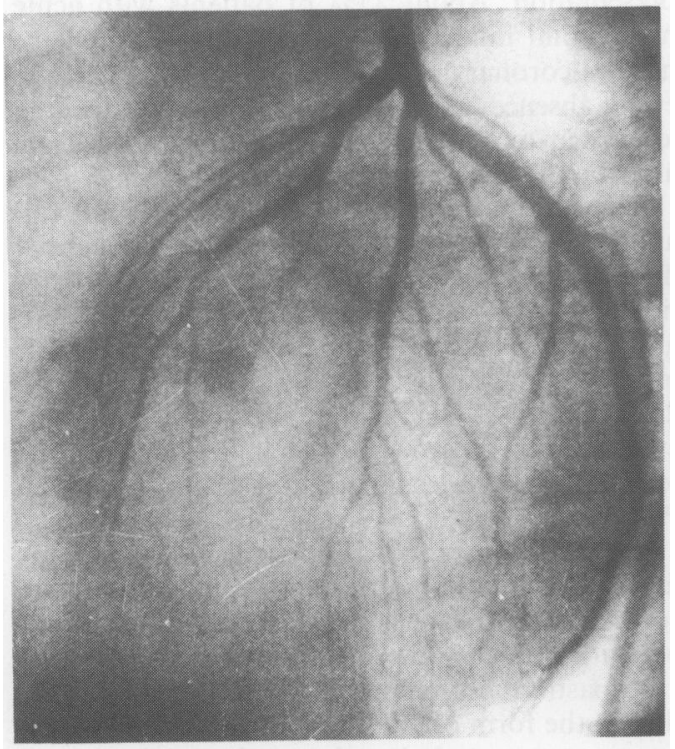

b

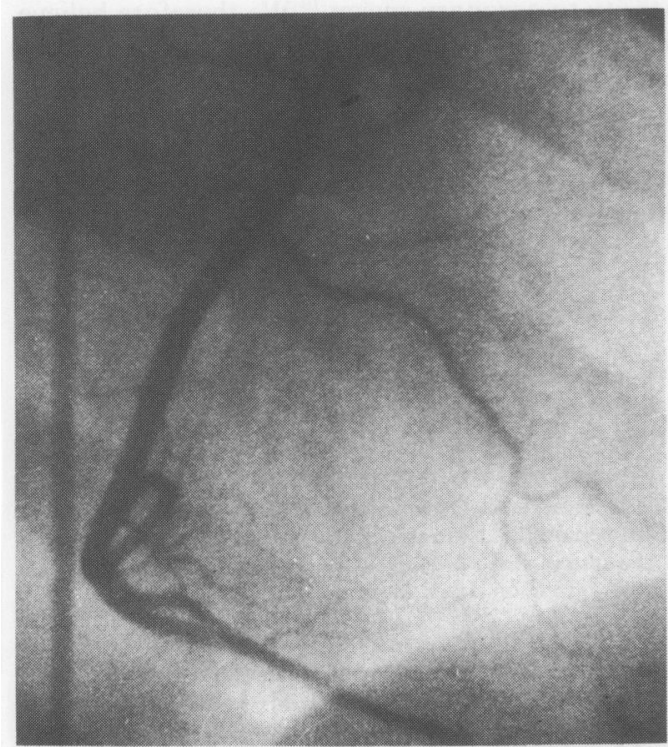

Figure 1 (a) Left and (b) right coronary angiograms showing normal coronary arteries.

nifedipine. He was not treated for PAN as steroids are known to increase the incidence of ventricular rupture, inhibit healing of the infarct and increase mortality ${ }^{3,4}$ and immunosuppressants could not be given because of his unwillingness for follow-up. Three months later he developed orchitis and refused testicular biopsy. He has no cardiovascular or other systemic symptoms at 6 months follow-up a

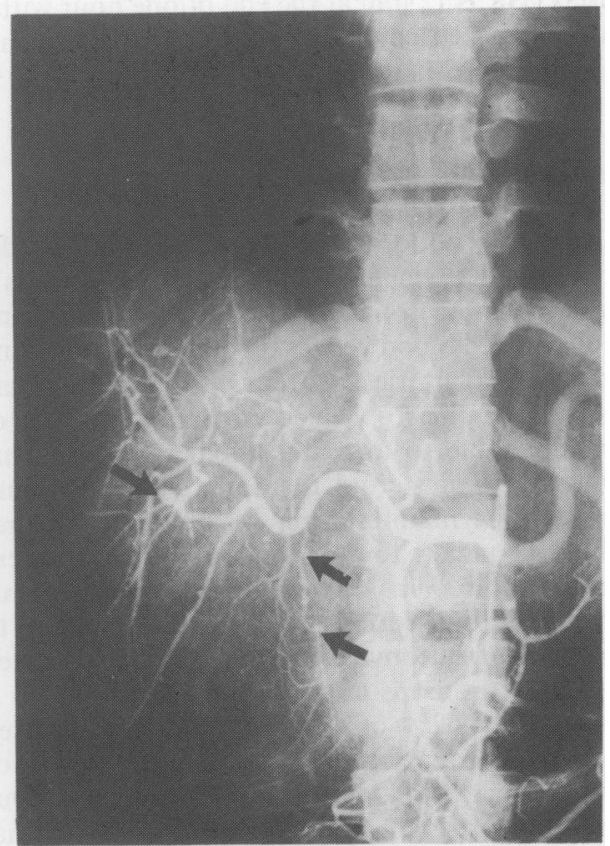

b

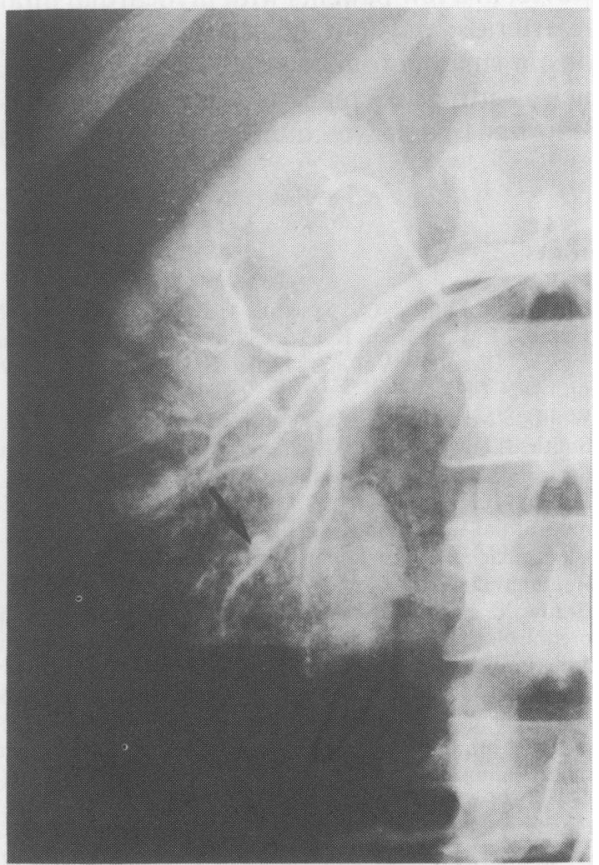

Figure 2 (a) Selective coeliac artery angiography showing microaneurysms of hepatic artery and its branches (arrows) and (b) selective right renal artery angiogram showing aneurysm (arrow) with evidence of infarction at the lower pole. 
and his blood pressure is well under control. His repeat ESR is $12 \mathrm{~mm}$ at the end of one hour with a total white cell count of $6.8 \times 10^{9} / 1(3 \%$ eosinophils).

\section{Discussion}

Polyarteritis nodosa in its classic form was described by Kussmaul and Maier in $1866 .{ }^{5}$ It is a multisystem necrotizing vasculitis of small and medium sized blood vessels involving the renal and other visceral arteries. ${ }^{4}$ Cardiac lesions in PAN can be primary, due to healed or active arteritis or secondary due to associated hypertension, renal involvement or steroid therapy. ${ }^{5}$ The most common cardiac manifestation is congestive cardiac failure secondary to coronary arteritis, hypertension or both. ${ }^{6}$ In our patient, haemodynamic decompensation could have been due, in part, to hypertension but myocardial infarction prompted us to think in terms of coronary arteritis which is found in $50-62 \%$ of the cases. ${ }^{5,6}$ In all reported cases with coronary involvement, there is partial or complete occlusion of the involved artery. ${ }^{2}$ Our patient, surprisingly, had angiographically normal coronary arteries. In $85 \%$ of cases, infarcts can be correlated with coronary artery involvement. ${ }^{6}$ However, in a few patients with myocardial infarction, arteritis may not be demonstrated due to lesions in small coronary vessels. Usually infarcts in such a setting are small. ${ }^{6}$ On the other hand, our patient had extensive anterior wall myocardial

\section{References}

1. Katz, P. \& Faucy, A.S. Systemic vasculitis. In Samter, M., Frank, M.M., Austen, K.F. \& Claman, H.N. (eds) Immunological Diseases, Vol. 2. Little Brown, Boston, 1988 , pp 1417-1422.

2. Wolff, S.M. Polyarteritis nodosa. In Wyngarden, J.B. \& Smith, L.H. (eds) Cecil Textbook of Medicine. W.B. Saunders, Philadelphia, 1988, pp. 2028-2030.

3. Bulkley, B.H. \& Roberts, W.C. Steroid therapy during acute myocardial infarction. A cause of delayed healing and of ventricular aneurysm. Am J Med 1974, 56: 244.

4. Hammerman, H., Kloner, R.A., Hale, S., Schoen, F.J. \& Brauwald, E. Dose-dependent effects of short term methylprednisolone on myocardial infarct extent, scar formation and ventricular function. Circulation 1983, 68: 446.

5. Kussmaul, A. \& Maier, K. Uber cine bischer nicht beschreibene eigen thumchche arteriener krankung die mit morbus brightii und rapid forts chreitender allgemeiner muskellahmung embergent. Dtsch Arch Klin Med 1886, 1: 484-494.

6. Fauci, A.S. The vasculitis syndromes. In: Braunwald, E., Isselbacher, K.J., Petersdorf, G.R., Wilson, J.D., Martin, J.B. \& Fauci, A.S. (eds) Harrison's Principles of Internal Medicine, Vol. 2. McGraw Hill, New York, 1987, pp. $1438-1441$. infarction and was in Killip's class III at the time of presentation. About $25 \%$ of patients with acute myocardial infarction below the age of 35 have normal coronary arteries on angiography. ${ }^{7}$ However, absence of angiographically documented lesions in our patient with evidence of systemic arteritis throws up interesting possibilities.

Myocarditis is seen in 3\% of patients with PAN $^{6}$ at autopsy and can present as regional myocardial dysfunction mimicking acute myocardial infarction clinically, enzymatically and electrocardiographically. ${ }^{8}$ Thus myocardial biopsy was mandatory in our patient who had normal coronary arteries. At histology, however, there was no evidence of myocarditis although this could be due to the segmental lesions characteristically seen in PAN. $^{2}$

In the absence of a documented cause for myocardial infarction, we are tempted to postulate coronary vasospasm as a cause of infarction in our patient. Patients with PAN are known for their vasospastic abnormalities in the peripheral circulation in the form of Raynaud's phenomen. ${ }^{9}$ Moreover, a recent study has shown that patients with Raynaud's phenomenon have an increased propensity to coronary spasm. ${ }^{10} \mathrm{We}$ therefore believe that coronary vasospasm may have caused myocardial infarction in our patient. This prompted us to use long term calcium channel blockers in this patient. The patient has no evidence of ongoing? myocardial ischaemia at 6 months after myocardial infarction.

7. Schrader, M.L., Hochman, J.S. \& Bulkley, B.H. The heart in polyartentis nodosa: a clinico-pathological study. Am Heart J 1985, 109: 1353-1359.

8. Holsinger, D.R., Osmondson, P.J. \& Edwards, J.E. The heart in periarteritis nodosa. Circulation 1962, 25: 610-618.

9. Pasternak, R.C., Braunwald, E. \& Sobel, B.E. Acute myocardial infarction. In: Braunwald, E. (ed.) Heart Disease - A Textbook of Cardiovascular Medicine, vol. 2. W.B. Saunders, Philadelphia, 1988, pp. 1222-1313.

10. Miklozek, C.L., Crumpacker, C.S., Royal, H.D., Come, P.C., Sullivan, J.L. \& Abelman, W.H. Myocarditis presenting as acute myocardial infarction. Am Heart J 1987, 115: 768-776.

11. Edwards, E.A. \& Coffman, J.D. Cutaneous changes in peripheral vascular disease. In: Fitzpatrick, T.B., Eisen, A.Z., Wolff, K., Freedberg, I.M. \& Austen, K.F. (eds) Dermatology in General Medicine. vol. 2. McGraw Hill, New York, 1987, p. 2002.

12. Miller, D., Waters, D.D., Warnica, W., Szlachcic, J., Kreeft, J. \& Theroux, P. Is variant angina the coronary manifestation of a generalised vasospastic disorder. $N$ Engl J Med 1981, 304: $763-766$. 


\section{Erratum}

"Acute myocardial infarction with normal coronary arteries in a case of polyarteritis nodosa: possible role of coronary artery spasm". R.M. Rajani, B.V. Dalvi, S.A. d'Silva, Y.Y. Lokhandwala and P.A. Kale Postgrad Med J 1991 67: 78-80.
The references in the Discussion section of this paper were incorrectly numbered and a sentence was omitted: the final pages should read as follows: and his blood pressure is well under control. His repeat ESR is $12 \mathrm{~mm}$ at the end of one hour with a total white cell count of $6.8 \times 10^{9} / 1(3 \%$ eosinophils). In the absence of biopsy evidence, the angiographic demonstration of involved vessels, particularly in the form of aneurysms of small- and medium-sized arteries in the renal hepatic and visceral vasculature is sufficient to make the diagnosis of polyarteritis nodosa. ${ }^{6}$ The demonstration of circulating hepatitis B antigen serves as important circumstantial evidence in support of the diagnosis.

\section{Discussion}

Polyarteritis nodosa in its classic form was described by Kussmaul and Maier in $1886 .^{5}$ It is a multisystem necrotizing vasculitis of small and medium sized blood vessels involving the renal and other visceral arteries. ${ }^{6}$ Cardiac lesions in PAN can be primary, due to healed or active arteritis or secondary due to associated hypertension, renal involvement or steroid therapy. ${ }^{7}$ The most common cardiac manifestation is congestive cardiac failure secondary to coronary artertis, hypertension or both. ${ }^{8}$ In our patient, haemodynamic decompensation could have been due, in part, to hypertension but myocardial infarction prompted us to think in terms of coronary arteritis which is found in $50-62 \%$ of the cases. $^{7,8}$ In all reported cases with coronary involvement, there is partial or complete occulsion of the involved artery. ${ }^{2}$ Our patient, surprisingly, had angiographically normal coronary arteries. In $85 \%$ of cases, infarcts can be correlated with coronary artery involvement. ${ }^{8}$ However, in a few patients with myocardial infarction, arteritis may not be demonstrated due to lesions in small coronary vessels. Usually infarcts in such a setting are small. ${ }^{8}$ On the other hand, our patient had extensive anterior wall myocardial infarction and was in Killip's class III at the time of presentation. About $25 \%$ of patients with acute myocardial infarction below the age of 35 have normal coronary arteries on angiography. ${ }^{9}$ However, absence of angiographically documented lesions in our patient with evidence of systemic arteritis throws up interesting possibilities.

Myocarditis is seen in $3 \%$ of patients with PAN $^{8}$ at autopsy and can present as regional myocardial dysfunction mimicking acute myocardial infarction clinically, enzymatically and electrocardiographically. ${ }^{10}$ Thus myocardial biopsy was mandatory in our patient who had normal coronary arteries. At histology, however, there was no evidence of myocarditis although this could be due to the segmental lesions characteristically seen in PAN. ${ }^{2}$

In the absence of a documented cause for myocardial infarction, we are tempted to postulate coronary vasospasm as a cause of infarction in our patient. Patients with PAN are known for their vasospastic abnormalities in the peripheral circulation in the form of Raynaud's phenomen. ${ }^{11}$ Moreover, a recent study has shown that patients with Raynaud's phenomenon have an increased propensity to coronary spasm. ${ }^{12} \mathrm{We}$ therefore believe that coronary vasospasm may have caused myocardial infarction in our patient. This prompted us to use long term calcium channel blockers in this patient. The patient has no evidence of ongoing myocardial ischaemia at 6 months after myocardial infarction.

\section{References}

1. Katz, P. \& Faucy, A.S. Systemic vasculitis. In Samter, M., Frank, M.M., Austen, K.F. \& Claman, H.N. (eds) Immunological Diseases, Vol. 2. Little Brown, Boston, 1988, pp 1417-1422.

2. Wolff, S.M. Polyarteritis nodosa. In Wyngarden, J.B. \& Smith, L.H. (eds) Cecil Textbook of Medicine. W.B. Saunders, Philadelphia, 1988, pp. 2028-2030. 
3. Bulkley, B.H. \& Roberts, W.C. Steroid therapy during acute myocardial infarction. A cause of delayed healing and of ventricular aneurysm. Am J Med 1974, 56: 244.

4. Hammerman, H., Kloner, R.A., Hale, S., Schoen, F.J. \& Brauwald, E. Dose-dependent effects of short term methylprednisolone on myocardial infarct extent, scar formation and ventricular function. Circulation 1983, 68: 446.

5. Kussmaul, A. \& Maier, K. Uber cine bischer nicht beschreibene eigen thumchche arteriener krankung die mit morbus brightii und rapid forts chreitender allgemeiner muskellahmung embergent. Disch Arch Klin Med 1886, 1: 484-494.

6. Fauci, A.S. The vasculitis syndromes. In: Braunwald, E., Isselbacher, K.J., Petersdorf, G.R., Wilson, J.D., Martin, J.B. \& Fauci, A.S. (eds) Harrison's Principles of Internal Medicine, Vol. 2. McGraw Hill, New York, 1987, pp. 1438-1441.

7. Schrader, M.L., Hochman, J.S. \& Bulkley, B.H. The heart in polyarteritis nodosa: a clinico-pathological study. Am Heart J 1985, 109: 1353-1359.
8. Holsinger, D.R., Osmondson, P.J. \& Edwards, J.E. The heart in periarteritis nodosa. Circulation 1962, 25: 610-618.

9. Pasternak, R.C., Braunwald, E. \& Sobel, B.E. Acute myocardial infarction. In: Braunwald, E. (ed.) Heart Disease - A Textbook of Cardiovascular Medicine, vol. 2. W.B. Saunders, Philadelphia, 1988, pp. 1222-1313.

10. Miklozek, C.L., Crumpacker, C.S., Royal, H.D., Come, P.C., Sullivan, J.L. \& Abelman, W.H. Myocarditis presenting as acute myocardial infarction. Am Heart $J$ 1987, 115: 768-776.

11. Edwards, E.A. \& Coffman, J.D. Cutaneous changes in peripheral vascular disease. In: Fitzpatrick, T.B., Eisen, A.Z., Wolff, K., Freedberg, I.M. \& Austen, K.F. (eds) Dermatology in General Medicine. vol. 2. McGraw Hill, New York, 1987, p. 2002.

12. Miller, D., Waters, D.D., Warnica, W., Szlachcic, J., Kreeft, J. \& Theroux, P. Is variant angina the coronary manifestation of a generalised vasospastic disorder. N Engl J Med 1981, 304: 763-766. 